DOI: https://doi.org/10.30749/2594-8261.v2n1p72-94

\title{
CARTA DA TERRA COMO MATERIAL DIDÁTICO ESTRATÉGICO'
}

\section{CARTA DA TERRA AS A STRATEGIC DIDACTIC MATERIAL}

\author{
Marilaine Bittencourt Mendesii \\ Kátia Eliane Santos Avelarii
}

\begin{abstract}
Resumo: A escola é um espaço coletivo e democrático que necessita trabalhar valores, além de conteúdos disciplinares, junto às crianças e jovens em relação à cidadania e à consciência ambiental. Assim, vários documentos e livros são indicados e adotados na escola como materiais que visam orientar valores. No presente artigo, argumentar-se-á sobre a importância de se trabalhar com a Carta da Terra, documento aprovado pela UNESCO, em Paris, em março de 2000, como instrumento estratégico com vistas a contribuir para que as crianças, desde as séries iniciais, compreendam a complexidade do planeta Terra e que possam valorizar o coletivo, a cidadania e a solidariedade humana.
\end{abstract}

Palavras-chave: Carta da Terra. Educação Ambiental. Educação Básica. Infância. Ética Ambiental.

Abstract: The school is a collective and democratic space that needs to work values, as well as disciplinary contents, with children and young people in relation to citizenship and environmental awareness. Thus, several documents and books are indicated and adopted in the school as materials that aim to guide values. In this study, we will argue about the importance of working with the Carta da Terra, a document approved by UNESCO in Paris in March 2000, as a strategic tool to help children, from the initial series, understand the complexity of planet Earth and that can value the collective, citizenship and human solidarity.

Keywords: Earth Charter. Environmental Education. Basic Education. Childhood. Environmental Ethics.

\footnotetext{
${ }^{\text {i }}$ Artigo publicado no livro "Cidadania e Educação Ambiental na Prática" com o título "Carta da Terra e uma nova Ética Ambiental".

ii Graduada em pedagogia pela Universidade Veiga de Almeida (1987) e pós graduação, em Problemas do Desenvolvimento Escolar pela Faculdade de Filosofia, Ciências e Letras de Duque de Caxias(1990). A segunda graduação em fonoaudiologia, pela Universidade Veiga de Almeida (1991). Mestre em Desenvolvimento Local pela UNISUAM (2017).

iii Mestre em Ciências Biológicas pela Universidade Federal do Rio de Janeiro (UFRJ) (1996). Doutora em Ciências também pela Universidade Federal do Rio de Janeiro (2002). Atualmente é coordenadora do Laboratório de Referência Nacional para Leptospirose do Instituto Oswaldo Cruz (FIOCRUZ). Professora Titular e Pesquisadora do Programa de Pós-Graduação Profissional Interdisciplinar em Desenvolvimento Local do Centro Universitário Augusto Motta (UNISUAM).
} 


\section{INTRODUÇÃO}

Este artigo é resultado de estudos realizados no âmbito da Educação ambiental e trata da utilização da Carta da Terra como instrumento pedagógico para o trabalho com crianças na escola. Sendo um espaço transformador, a escola é responsável pelo desenvolvimento de processos cognitivos e afetivos na internalização de conceitos para o desenvolvimento da criança e sua formação moral. Além de contribuir para a formação de indivíduos críticos, desde os períodos iniciais da educação formal.

A Carta da Terra como recurso pedagógico amplia os conhecimentos das crianças e suas vivências, na compreensão da importância do trabalho da Educação Ambiental na escola para a mudança de comportamento em valores morais, éticos, com atitudes autônomas e o cumprimento de conceitos de preservação ambiental e de sustentabilidade. Assim como as crianças, os professores, pais, comunidade e todos os demais personagens envolvidos, devem refletir sobre atitudes e valores éticos ambientais para alcançar uma vida mais sustentável, igualitária e inclusiva, com respeito e preservação dos diferentes espaços naturais.

A temática ambiental e desenvolvimento sustentável, em instituições de ensino, são de grande importância, pois imprime como estratégia, as melhores ferramentas para a aquisição de valores ecoéticos, de forma a fortalecer a interação entre sociedade e natureza. Neste sentido, o trabalho emerge com a questão da importância da Educação Ambiental com crianças a partir de 8 de idade, pois segundo Piaget, nessa idade é que as crianças se encontram na última fase do desenvolvimento moral para a legitimação e respeito a regras e valores éticos.

A abordagem preconizada pelas teorias de Piaget, Kohlberg, Wallon e Vygotsky, entre outros autores como GADOTTI (2000, 2009), GALVÃO (2000), QUINTAS (2000), MENIM (2007) e BOFF (2012) pautam um princípio comum, que é favorecer por meio da Educação Ambiental a transformação socioambiental, minimizando as injustiças e as desigualdades socioambientais e, como consequência, fortalecer o futuro. 


\section{O PROCESSO DE ENSINO-APRENDIZAGEM NA FASE INICIAL DA EDUCAÇÃO}

Para Piaget, o desenvolvimento mental da criança se dá de forma espontânea, a partir de suas potencialidades e da sua interação com o meio. Tal processo mental é lento, ocorre por meio de graduações sucessivas em estágios. Ou seja, para ele, a interação com os diversos ambientes sociais é diária e constrói os valores, princípios e normas morais. O que se entende que é um processo que requer tempo. Nessa visão, o desenvolvimento cognitivo, que é a base da aprendizagem, se dá por assimilação e acomodação.

É muito difícil, se não impossível, imaginar uma situação em que possa ocorrer assimilação sem acomodação, pois dificilmente um objeto é igual a outro já conhecido, ou uma situação é exatamente igual a outra. (TERRA, 2006, p. 7)

Para Piaget, na assimilação, quando a criança não consegue assimilar determinada situação, a mente desiste ou se modifica. Ao se modificar, surge a acomodação, levando a construção de novos esquemas de assimilação e resultando no processo de desenvolvimento cognitivo. Somente poderá ocorrer a aprendizagem quando o esquema de assimilação sofre acomodação. (MOREIRA, 1995).

Então, para Piaget apenas a acomodação vai promover descoberta e, assim, a construção do conhecimento. Em sua afirmativa, é preciso propor, no contexto escolar, atividades desafiadoras que provoquem desequilíbrios e reequilibrações sucessivas nos alunos. O conhecimento real e concreto é construído por meio de experiências.

O papel do educador, mediante essa concepção, é o de criar situações que envolvam o aluno, conforme o seu nível de desenvolvimento cognitivo. Piaget ensina que o desenvolvimento se divide em quatro fases: período da inteligência sensóriomotora (até os 2 anos); período da inteligência pré-operacional (dos 3 aos 7 anos); período da inteligência operatório-concreto (dos 8 aos 11 anos); e período da inteligência operatório-formal (a partir dos 12 anos). (MOREIRA, 1995).

Nesse processo é possível, ainda, entender as orientações voltadas para a 
moralidade em que para as crianças menores, as regras são leis sagradas e imutáveis, uma vez impostas pelos adultos e obedecidas sem questionamentos. Já, as maiores, a partir dos 8 anos, passam aos poucos para um estágio de autonomia, em que as regras são vistas como resultado de uma decisão livre e digna de respeito, aceitas pelo grupo. (PIAGET, 1997).

Toda a moral é formada por um sistema de regras e a moralidade consiste no respeito que o indivíduo nutre por estas regras. Diz que o desenvolvimento da moralidade se dá principalmente através da atividade de cooperação, do contato com iguais, da relação com companheiros e do desenvolvimento da inteligência (PIAGET, 1997)

Ao observar o comportamento das crianças, através dos jogos e das regras neles impostas, verifica que esses jogos, sinalizam a moralidade humana por três razões:

I - Representam uma atividade interindividual reguladora por certas normas que mesmo herdadas das gerações anteriores podem ser modificadas pelos membros de cada grupo de jogadores.

II - Às vezes, as normas não possuem caráter moral, em si, o respeito a elas é, ele sim, moral e envolve questões de justiça e honestidade.

III - O respeito provém de mútuos acordos entre os jogadores e não da mera aceitação de normas impostas por pessoas de fora à comunidade e jogadores. (PIAGET, 1997, p.2)

Ainda segundo Piaget (1994), a classificação da evolução dessa consciência e do desenvolvimento moral apresenta-se pela Anomia, quando há ausência de regra, ou seja, a moral encontra-se fora do universo de valores da criança. A Heteronomia, quando há visão unilateral na compreensão das situações, havendo um entendimento literal das regras, sendo estas, fruto de imperativos colocados pelos adultos (autoridades) e subsistentes em si, e um posicionamento mais egocêntrico ao julgar ações. Há autonomia quando há presença de posicionamentos que refletem cooperação e respeito mútuo no julgamento das ações, desenvolvimento da capacidade de se colocar no lugar do outro, e de perceber a intencionalidade das ações, demonstrando gradativa elevação da capacidade de 
descentração.

O saber é construído por sua interação com o meio e requer tempo, em nenhum momento é imposto de fora. Nessa perspectiva, o desenvolvimento moral é concomitante ao desenvolvimento lógico, com aspectos paralelos de um mesmo processo geral de adaptação.

ARAGUAIA (2015), em sua discussão sobre Piaget, enfatiza que cabe ao professor, mediante o conhecimento de que as crianças e adolescentes seguem fases mais ou menos parecidas quanto ao desenvolvimento moral, compreender que há determinadas formas de lidar com diferentes situações em diferentes faixas etárias. Assim, é preciso conduzir seu aluno na transição anomia - heteronomia, encaminhando-se naturalmente para a sua própria autonomia moral e intelectual.

Vale lembrar que, mais uma vez na concepção de Piaget, a educação moral não é vista como uma matéria especial de ensino, mas um aspecto particular da totalidade do sistema, então, entende-se que as crianças e os jovens não devem ter "aulas" de educação moral, mas vivenciar a moralidade em todos os aspectos e ambientes presentes no espaço escolar e fora dele. O que é possível verificar nos trabalhos em grupos, pois estes facilitam a construção da autonomia, através de trocas entre eles, como expor ponto de vista, discutir, saber ganhar nas ideias e perder em outras, enfim, exercer a democracia. Propiciar aos alunos, situações em que vivencies cooperação, reciprocidade e respeito. Essa é a construção da moralidade para Piaget. (ARAGUAIA, 2015).

Novas diretrizes para a educação moral, ou da ética, nas escolas, foram explicitadas recentemente pelos Parâmetros Curriculares Nacionais e baseadas nas teorias de Piaget, que com suas descobertas indica implicações para a educação moral e ética nas escolas.

Se educar moralmente significa a busca de autonomia, e se autonomia significa a capacidade de construir valores e regras com os quais se concorda em se submeter, considerando os benefícios para o maior número de envolvidos, então, como diz Piaget, os métodos dessa educação moral são fundamentais e, necessariamente, não podem ser autoritários, mas ativos, levando à construção da autonomia moral. (MENIM, 2007, p. 57) 
A autora explica que o próprio Piaget aconselhava, em relação à construção da autonomia moral, não impor à criança aquilo que ela pode descobrir por si e criar situações para que ela descubra a necessidade e as razões das regras. (MENIM, 2007)

Prosseguindo nos estudos, vale destacar que assim como Piaget, Lawrence Kohlberg (1958) também dominou pesquisas sobre desenvolvimento moral de maneira cognitivista, porém criou os estágios, pois acreditava que o nível mais alto da moralidade exige estruturas lógicas novas e mais complexas do que as apresentadas por Piaget.

Kohlberg apresentou a moralidade em três níveis. O primeiro, chamado de nível pré-convencional, se caracteriza pela moralidade heterônoma, que conforme explica Aranha e Martins (2003, p. 311): "as regras morais derivam da autoridade, são aceitas de forma incondicional e a criança obedece a fim de evitar castigo ou para merecer recompensa". Neste estágio, diz ainda, que a criança define a justiça em função de diferenças de poder e status, sendo incapaz de diferenciar perspectivas nos dilemas morais. Já no segundo, nível convencional, valoriza-se o reconhecimento do outro, período que surge a moralidade normativa interpessoal e a moralidade do sistema social.

Momento em que a criança segue as regras para garantir seu bom desempenho de "bom menino" e de "boa menina" e a partir daí ele adota a perspectiva de um membro da sociedade baseada em uma concepção do sistema social como um conjunto consistente de códigos e procedimentos que se aplicam imparcialmente a todos os seus membros. (DÍAZ-AGUADO; MEDRANO, 1999, p. 31)

O terceiro e último é chamado de nível pós-convencional, considerado por Kohlberg, como o mais alto da moralidade, pois o indivíduo começa a perceber os conflitos entre as regras e o sistema, o qual compreende o estágio da moralidade dos direitos humanos e o estágio dos princípios éticos universais.

Neste ponto, os comportamentos morais passam a ser regulados por princípios, "os valores independem dos grupos ou das pessoas que os sustentam, porque são princípios universais de justiça: igualdade dos direitos humanos respeito, à dignidade das pessoas (...)" (ARANHA; MARTINS, 2003, p. 312). 
Dentro da pesquisa dos filósofos citados, vale destacar Henry Wallon, que em sua tese remete o fato de que a criança é um ser único e deve-se observar nesta, não apenas as semelhanças, mas também as diferenças.

Para Wallon (1995), mediante Galvão (2000), a criança, é essencialmente emocional e gradualmente vai constituindo-se em um ser sócio-cognitivo. O autor estudou a criança contextualizada, como uma realidade viva e total no conjunto de seus comportamentos, suas condições de existência. (WALLON, 1995).

GALVÃO (2000) esclarece que Wallon também propõe estágios de desenvolvimento, assim como Piaget, porém, ele não é adepto da ideia de que a criança cresce de maneira linear. O desenvolvimento humano tem momentos de crise, isto é, uma criança ou um adulto não são capazes de se desenvolver sem conflitos. A criança se desenvolve com seus conflitos internos e, para ele, cada estágio estabelece uma forma específica de interação com o outro, é um desenvolvimento conflituoso.

De tudo isso, até aqui analisado, registra-se que o início da vida de uma criança é formado pelos valores dos adultos, que serão transmitidos e interagidos pela família e escola. Por tanto, é nesta pauta que se deve avaliar a construção da moral e da ética que são introduzidas no ser humano, futuro adulto, desde a sua infância, elevando assim o grau de responsabilidade aos envolvidos no processo de aprendizagem.

Dentro deste prisma, surge a questão da ética, que também deve ser ministrada desde cedo. Porém, sabe-se da dificuldade em se trabalhar o princípio da ética com as crianças menores, uma vez que estão, ainda, começando a compreender seus atos.

Já elucidava Freire (2003) que pensar certo e tomar decisões certas exigem uma postura ética com relação às interpretações dos fatos. Então, é evidente que o educador que pretende transmitir uma postura ética, precisa demonstrá-la em seu comportamento e em suas atitudes no contexto escolar.

IMBERT (2002) aponta que: "a ética mostra que a relação não visa o controle do outro e a apropriação do saber da comunidade em que está inserido o sujeito". A relação entre homem e mundo é uma relação mediada, na qual, entre o homem e o mundo existem elementos que auxiliam a atividade humana. A 
capacidade humana para a linguagem faz com que as crianças providenciem instrumentos que auxiliem na solução de tarefas difíceis, planejem uma solução para um problema e controlem seu comportamento. (VYGOTSKY, 1989).

Em concordância com os estudos, destaca-se a intenção de pesquisar a possibilidade de desenvolver nas crianças valores ambientais, importantes e altamente necessários no contexto atual, porém entende sua definição, mas se confronta com o inesgotável, com o infinito das pessoas e das situações (IMBERT, 2002, p. 95).

Aranha e Martins (2003, p. 235) complementam o exposto "a nova ética analisa as ações não mais em função de uma hierarquia de valores dada a priori, mas sim em vista das consequências, dos resultados da ação política". Então, a ética não é apenas seguir as regras despejadas a nós seres humanos, mas ter consciência do porque estamos cumprindo-as, pois como explica Imbert (2002) a ética substitui a perspectiva moral da fabricação de hábitos. Fomos educados a seguir as regras, mas não a refletir sobre elas.

Segundo Vygotsky (1987), o homem se produz na e pela linguagem, isto é, é na interação com outros sujeitos que formas de pensar são construídas, e mais do que informações e conceitos, a escola deve se se dispor a trabalhar com atitudes, com formação de valores e com mais ações práticas para que desde cedo, a criança aprenda a respeitar e praticar ações voltadas à conservação ambiental. A escola é o lugar onde o aluno irá dar sequência ao seu processo de socialização, no entanto, comportamentos ambientalmente corretos devem ser aprendidos na prática, no decorrer da vida escolar com o intuito de contribuir para a formação de cidadãos responsáveis.

E é nesse processo de formação, que a Educação Ambiental deverá permear todas as áreas do conhecimento de modo interdisciplinar, com reflexão de práticas educativas que integrem as disciplinas e que contextualizam o conhecimento.

\section{INTERDISCIPLINARIDADE E EDUCAÇÃO AMBIENTAL}

Tavares (2002) afirma que a Educação Ambiental se caracteriza por ter um 
enfoque interdisciplinar, onde as condutas em relação ao entorno devem estar em constante aprendizado, e que seja viável de seguir na direção a uma nova ética, sensibilizadora e transformadora para as relações integradas homem/sociedade/meio ambiente, conforme pode ser visualizada na figura 3 abaixo.

Figura 3 - Relações integradas homem/sociedade/meio ambiente

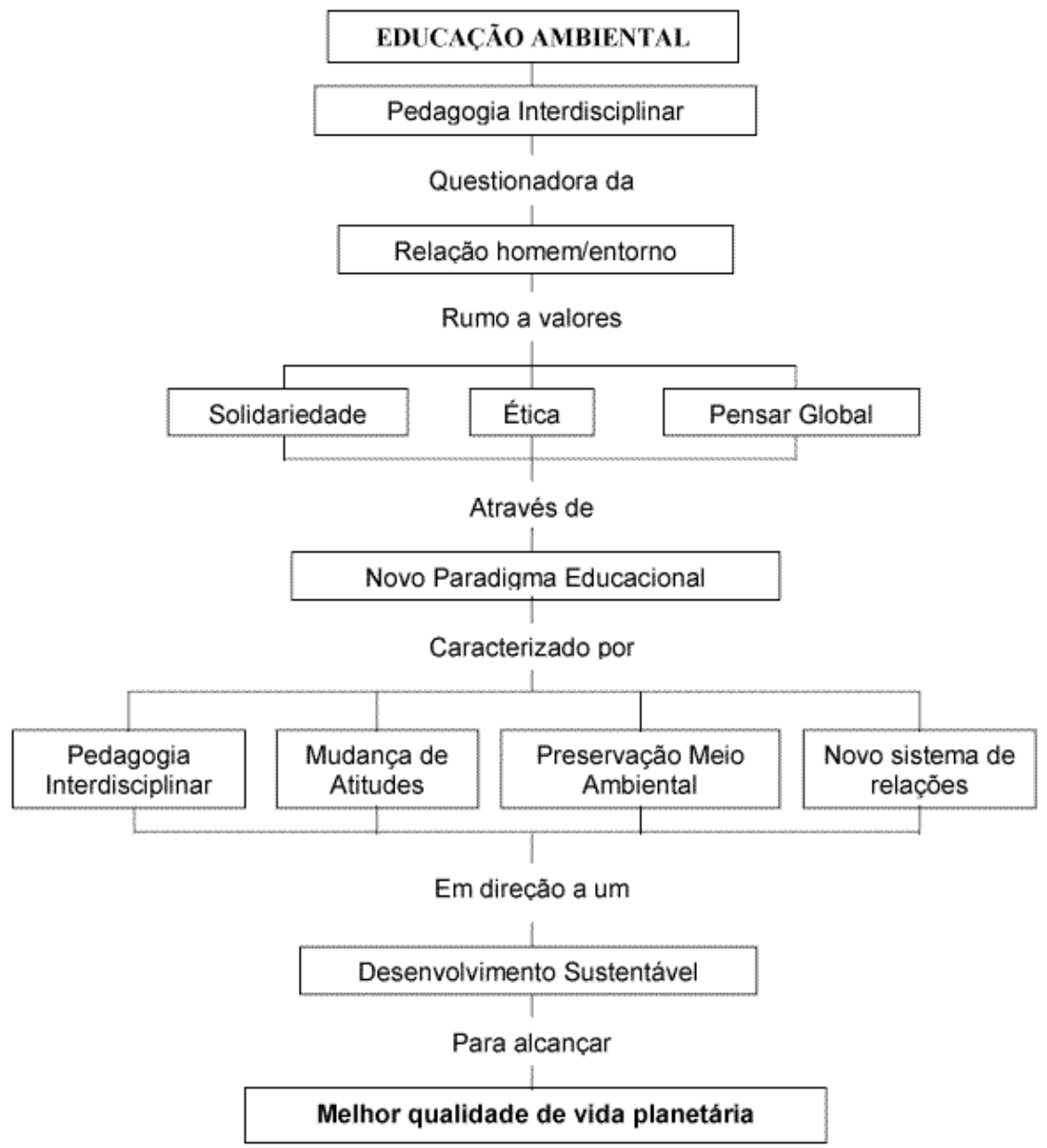

Fonte: http://www.efdeportes.com

Para Pereira (2014), a educação ambiental com a perspectiva interdisciplinar, proporciona a oportunidade de uma compreensão em relação aos fatores ambientais a partir de um processo que progride de maneira coletiva e integral. E, ainda, proporciona a compreensão da complexidade natural do ambiente e do ser humano em suas mútuas relações, e das transformações resultantes da interação entre aspectos biológicos, físicos, sociais, econômicos e culturais. Sem 
contar que: "oferece meios para o desenvolvimento de conhecimentos, comportamentos e habilidades práticas necessárias à participação responsável e eficaz nos processos de conservação e busca de solução dos problemas ambientais". (PEREIRA, 2014, p. 580).

A interdisciplinaridade não dilui as disciplinas, ao contrário, mantém sua individualidade. Mas integra as disciplinas a partir da compreensão das múltiplas causas ou fatores que intervêm sobre a realidade e trabalha todas as linguagens necessárias para a constituição de conhecimentos, comunicação e negociação de significados e registro sistemático dos resultados. (BRASIL, 1999, p. 89)

Vale destacar, neste contexto, que o procedimento interdisciplinar estabelecerá, junto das práticas ambientais e do desenvolvimento do trabalho didático-pedagógico, a possibilidade de divulgação e de reedificação dos conteúdos disciplinares, experimentando a transformação do diferente em relação ao outro. "A interdisciplinaridade não se trata de simples cruzamento de coisas parecidas, tratase, de Constituir e Construir diálogos fundamentados na diferença, amalgamando concretamente a riqueza da diversidade". (COIMBRA, 2010, p. 2).

O autor adverte que para haver condição de efetivação da Interdisciplinaridade, é preciso desenvolver sentidos, pressupondo um treino na arte de entender, sentir e esperar, um desenvolvimento no sentido de criação e imaginação. E assim, cita-os: "Fronteira, Atitude, Identidade, Olhar, Humildade, Mudança, Ponte, Contextualização e Coerência. Sentidos esses, que se refere a vários aspectos formais e não formais da Interdisciplinaridade". (COIMBRA, 2010, p. $3)$.

No entanto, compreende-se, em seus relatos, que é preciso interagir esses conceitos para que seja possível a confirmação do ato interdisciplinar e, também, que essa interação não venha apenas pela integração de conteúdos, mas em integração de conhecimentos parciais e específicos.

A Interdisciplinaridade pressupõe basicamente: (...) uma intersubjetividade, não pretende a construção de uma superciência, mas uma mudança de atitude frente ao problema do conhecimento, uma substituição da concepção fragmentária para a unitária do ser humano. (FAZENDA, 2002, p. 40). 
A Interdisciplinaridade é um termo utilizado para:

(...) caracterizar a colaboração existente entre disciplinas diversas ou entre setores heterogêneos de uma mesma ciência (Exemplo: Psicologia e seus diferentes setores: Personalidade, Desenvolvimento Social etc.). Caracteriza-se por uma intensa reciprocidade nas trocas, visando um enriquecimento mútuo. (FAZENDA, 2002, p. 41).

Mais uma vez, Coimbra (2010, p. 3) contribui ao expor que o comportamento interdisciplinar tenciona:

Superar a fragmentação do conhecimento. Entretanto, esse é um importante viés a ser perseguido pelos educadores ambientais, onde se permite, pela compreensão mais globalizada do ambiente, trabalhar a interação em equilíbrio dos seres humanos com a natureza.

Ou seja, a interdisciplinaridade favorece que as disciplinas se comuniquem entre si, possibilitando o entendimento de processos históricos e culturais que levam à percepção contextualizada do homem no seu meio natural. De acordo com BRASIL (1999), a reorganização curricular em áreas de conhecimento tem o objetivo de facilitar o desenvolvimento dos conteúdos, numa perspectiva de interdisciplinaridade e contextualização. A proposta da interdisciplinaridade é estabelecer ligações de complementaridade, convergência, interconexões e passagens entre os conhecimentos. O currículo deve contemplar conteúdos estratégias de aprendizagem que capacitem o aluno para a vida em sociedade, a atividade produtiva e experiências subjetivas, visando à integração.

Em torno de todo este debate, foi elaborado os Parâmetros Curriculares Nacionais (PCN) sobre Meio Ambiente, na qual, vem discutir sobre a temática ambiental a ser desenvolvido num ambiente escolar e tem a finalidade de estabelecer uma referência curricular para o professor e apoiar a revisão e/ou a elaboração da proposta curricular dos Estados ou das escolas integrantes dos sistemas de ensino.

A instituição educacional deve atentar, em seu planejamento inicial de ano, 
que pode contribuir através de adaptações das áreas com as questões ambientais, por meio de uma forma própria de compreensão desse tema, de exemplos abordados sobre o ponto de vista de seu universo de conhecimentos e pelo apoio teórico-instrumental das teorias pedagógicas do profissional professor.

Assim, atuará corretamente na sua função de oferecer oportunidades para que os alunos se exercitem no desempenho da cidadania e, mais ainda, para que seu estabelecimento educacional saiba como assumir sua responsabilidade como parte da sociedade local instituída e quais meios serão utilizados para alcançar os objetivos propostos em relação a questão.

Atualmente, alunos de escolas públicas e particulares de todo o país usam a internet para discutir questões ligadas ao meio ambiente, como a destinação do lixo ou o aquecimento do planeta. A utilização da tecnologia como ferramenta pedagógica tornou-se possível após a criação de uma comunidade virtual para debater os temas da $3^{a}$ Conferência Nacional Infanto-Juvenil pelo Meio Ambiente. (BRASIL, 2008)

Existe uma grande demanda dos sistemas de ensino, educadores, alunos e cidadãos a respeito da Educação Ambiental no ensino formal, devido à percepção da premência do enfrentamento dos complexos desafios ambientais. Devem ser consideradas as necessidades planetárias, as discussões, avanços históricos e experiências acumuladas quanto à temática no Brasil e no âmbito internacional. Todo este contexto fortalece o reconhecimento do papel transformador $\mathrm{e}$ emancipatório da Educação Ambiental, exigindo a revisão da referência superficial da transversalidade e da interdisciplinaridade contida na sua normatização para o ensino formal, que se apresenta desconexa, reducionista, desarticulada e insuficiente. (BRASIL, 2013)

\section{A CARTA DA TERRA E O DESAFIO NA CONSTRUÇÃO DE UM PENSAMENTO CRÍTICO}

O movimento para a sustentabilidade e preservação ambiental envolve uma ação, com indivíduos e coletividades, de determinada valoração ética para a construção de ideais democráticos embasados pela justiça econômica e social. 
A preocupação com o meio ambiente e as questões ecológicas, de certa forma, iniciou após a Segunda Guerra Mundial, pelas consequências e prejuízos deixados, primeiro pela preparação bélica e seus lixos industriais, e depois pela ampla devastação de espaços ambientais e sociais.

O pacto de todos os indivíduos com o futuro literalmente se formalizou em 1972, por intermédio das Nações Unidas, antiga Sociedade das Nações, ao organizar diferentes grupos da sociedade civil para discutir questões do meio ambiente. A Conferência das Nações Unidas gerou a Declaração de Estocolmo, pela qual limitou-se somente a pautar as consequências de degradação do ar e da água.

A Carta do Mundo para a Natureza surgiu, em 1982, fomentada pela Assembleia das Nações Unidas, para evoluir o seu conteúdo em direção às consequências ambientais intimamente ligadas às questões econômicas e sociais, entretanto sem abordar ainda os valores ecoéticos.

A partir dessa Carta do Mundo e da criação de uma Comissão Mundial para o Meio Ambiente e o Desenvolvimento, em 1987, foi apresentado um relatório na Assembleia Geral da ONU, conhecido como Relatório Brundtland, chefiado por Gro Harlem Brundtland, ex-primeiro ministro da Noruega, que trazia em seu conteúdo assuntos mais calcados no crescimento urbano e seus decorrentes problemas econômicos e sociais.

Em 1992, houve a Conferência sobre Meio Ambiente e o Desenvolvimento, na cidade do Rio de Janeiro. O Fórum da Terra, como essa Conferência também era conhecida, não conseguiu a aprovação do esboço da Carta da Terra, limitando-se apenas à Declaração do Rio sobre o Meio Ambiente e Desenvolvimento.

Após essa Conferência, várias Comissões e Conselhos foram formados ao longo dos anos para iniciar a redação da Carta da Terra, mediante consulta e consenso de vários povos. E, somente em 1997, constituiu-se a primeira comissão efetiva para elaboração da Carta da Terra, com trabalhos divididos, participação e contribuição de mais de 40 países, além de discussões nos diferentes campos do conhecimento para as problemáticas do desenvolvimento e preservação ambiental.

Somente nos anos 2000 é que a versão final da Carta da Terra foi publicada: 
O texto inclui: a) Preâmbulo propondo uma visão, uma análise e um desafio à nossa situação mundial atual; b) quatro Princípios Fundamentais (estruturados) como títulos para as Partes I, II, III e IV; c) quatro Princípios Gerais iniciais, representando compromissos amplos, articulados na Parte l; d) doze ulteriores Princípios Gerais, articulados nas Partes II, III e IV, necessários para tornar efetivos os quatro amplos compromissos estabelecidos na Parte I; e) sessenta e um Princípios de suporte, derivados dos dezesseis Princípios Gerais, para dar-Ihes uma direção concreta; f) uma Conclusão intitulada Um novo início. (FERRERO; HOLLAND, 2004, p. 75).

A Carta da Terra não nasceu de um projeto de lei, mas foi organizada pela sociedade civil, apresentando um caráter normativo e fundamentada por princípios morais, religiosos e filosóficos. Sua construção, de conteúdo global, é reconhecida como importante instrumento educacional pelos países membros da UNESCO.

Após o texto introdutório como o Preâmbulo, a Carta apresenta mais quatro textos citados como Terra - nosso lar; A situação Global; Desafios para o futuro e a Responsabilidade universal. A seguir, sua estrutura é dividida em quatro descritores que abordam o Respeito e cuidado com a comunidade de vida; Integridade ecológica; Justiça econômica e social; e Democracia, não-violência e paz. (CURRY, 2011, p. 125).

Os dezesseis princípios, descritos na Carta, são acompanhados por outros sessenta e um subprincípios e intitulam-se: 1. Respeitar a Terra e a vida em toda sua diversidade. 2. Cuidar da comunidade da vida com compreensão, compaixão e amor. 3. Construir sociedades democráticas que sejam justas, participativas, sustentáveis e pacíficas. 4. Garantir as dádivas e a beleza da Terra para as atuais e as futuras gerações. 5. Proteger e restaurar a integridade dos sistemas ecológicos da Terra, com especial preocupação pela diversidade biológica e pelos processos naturais que sustentam a vida. 6. Prevenir o dano ao ambiente como o melhor método de proteção ambiental e, quando o conhecimento for limitado, assumir uma postura de precaução. 7. Adotar padrões de produção, consumo e reprodução que protejam as capacidades regenerativas da Terra, os direitos humanos e o bem-estar comunitário. 8. Avançar o estudo da sustentabilidade ecológica e promover a troca aberta e a ampla aplicação do conhecimento adquirido. 9. Erradicar a pobreza como um imperativo ético, social e ambiental. 10. Garantir que as atividades e instituições econômicas em todos os níveis promovam o desenvolvimento humano de forma 
equitativa e sustentável. 11. Afirmar a igualdade e a equidade de gênero como prérequisitos para o desenvolvimento sustentável e assegurar o acesso universal à educação, assistência de saúde e às oportunidades econômicas. 12. Defender, sem discriminação, os direitos de todas as pessoas a um ambiente natural e social, capaz de assegurar a dignidade humana, a saúde corporal e o bem-estar espiritual, concedendo especial atenção aos direitos dos povos indígenas e minorias. 13. Fortalecer as instituições democráticas em todos os níveis e proporcionar-lhes transparência e prestação de contas no exercício do governo, participação inclusiva na tomada de decisões, e acesso à justiça. 14. Integrar, na educação formal e na aprendizagem ao longo da vida, os conhecimentos, valores e habilidades necessárias para um modo de vida sustentável. 15. Tratar todos os seres vivos com respeito e consideração. 16. Promover uma cultura de tolerância, não violência e paz.

Em razão de a Carta da Terra ser um importante documento crítico, de reflexão e com força de poder para que Estados cumpram seus princípios gerais, ainda assim, o seu conteúdo apresenta pontos que necessitam de uma intermediação, principalmente quanto à discussão dentro das escolas, para que seu texto e contexto sejam claramente entendidos pelos alunos.

\subsection{Carta da Terra: Instrumento de trabalho na educação ambiental}

A Carta da Terra diz o que devemos fazer para cuidar do mundo: respeitar a natureza, os direitos humanos, providenciar para que todos tenham o que necessitam para viver e empenhar-se para viver sempre em paz e harmonia.

Defende a ideia de sermos cidadãos do planeta de nos importarmos com todo e qualquer ser vivo e com o presente e futuro da Terra. E que todos os povos da Terra são irmãos e compartilham a responsabilidade de preservar e melhorar o mundo em que vivemos.

Nos anos de 1992, durante o evento da Cúpula da Terra, Rio 92, houve a elaboração da primeira versão da Carta. Somente após oito anos, em um processo participativo em todos os continentes e que contou com a contribuição de milhares de pessoas de todas as raças, credos, idades e profissões, incluindo especialistas 
em ciências, filosofia, ética, religiões e leis internacionais, é que a versão final foi lançada no Palácio da Paz em Haia, em vinte e nove de junho do ano dois mil, quando também foi assumida pela Unesco.

Gadotti (2010, p. 13), em seu livro "A Carta da Terra na Educação", afirma que o Brasil é o berço da Carta da Terra quando em 1992, no Fórum Global Rio-92, mais de mil e trezentos movimentos sociais e organizações iniciaram uma campanha chamada "Nós somos a Terra", pela adoção da carta e que consta na primeira redação da mesma.

Nós somos a Terra, os povos, as plantas e animais, gotas e oceanos, a respiração da floresta e o fluxo do mar. Nós honramos a Terra, como o lar de todos os seres viventes. Nós estimamos a Terra, pela sua beleza e diversidade de vida. Nós louvamos a Terra, pela sua capacidade de regeneração, sendo a base de toda a vida. Nós reconhecemos a especial posição dos povos indígenas da Terra, seus territórios e seus costumes, e sua singular afinidade com a Terra. Nós reconhecemos que o sofrimento humano, pobreza e degradação da Terra são causados pela desigualdade do poder. Nós aderimos a uma responsabilidade compartilhada de proteger e restaurar a Terra para permitir o uso sábio e equitativo dos recursos naturais, assim como realizar o equilíbrio ecológico e novos valores sociais, econômicos e espirituais. Em nossa inteira diversidade somos unidade. Nosso lar comum está crescentemente ameaçado. Assim sendo, levando em consideração sobretudo as necessidades especiais das mulheres, povos indígenas, do Sul, dos diferentes capacitados e de todos aqueles que se encontram em situação de desfavorecimento, nos comprometemos a (...). (LA ROVÈRE; VIEIRA, 1992, p.31)

Ainda segundo Gadotti (2010, p.19), a Carta da Terra foi adota por países como a Holanda, Costa Rica, e México e cidades como Xangai, Estocolmo e Seattle. No Brasil, através do Instituto Paulo Freire, a Carta da Terra é disseminada em diferentes espaços sociais e culturais por meio de uma ecopedagogia ética para um desenvolvimento sustentável.

A Carta da Terra é utilizada como um guia de cultura da paz e da sustentabilidade. Seria difícil apresentar um rol completo de atividades desenvolvidas no Brasil desde 1992. O Brasil é um vasto 
país e as iniciativas envolvendo a Carta da Terra multiplicam-se por todo o território. (GADOTTI, 2010, p. 29)

A Carta da Terra reflete um consenso crescente na emergente sociedade civil, de forma global, portanto, é preciso que seja trabalhada nas escolas, já que seus criadores acreditam que o desenvolvimento sustentável ou maneiras sustentáveis de vida requerem mudanças nos corações e nas mentes dos indivíduos, assim como na reorientação de políticas e práticas públicas. Apresenta, assim, uma estrutura integrada e coerente para desenvolver programas e currículos educacionais que visam o ensino e o aprendizado de um mundo mais justo, sustentável e pacifico. (EARTH CHARTER INTERNATIONAL, 2009)

A abordagem integrada promovida pela Carta da Terra enfatiza as relações entre os diferentes desafios enfrentados pela humanidade, que vão da erradicação da pobreza à proteção dos sistemas ecológicos da Terra e até a eliminação de todas as formas de discriminação. Ela pode ajudar a gerar relacionamentos mais empáticos entre os humanos e entre os humanos e o mundo natural. Pode facilitar a procura criativa de formas de desenvolvimento que sejam mais ambientalmente e socialmente responsáveis. (EARTH CHARTER INTERNATIONAL, 2009)

A educação é chave para avançar a transição para maneiras mais sustentáveis de viver. É o caminho adequado para as transformações e alcance de novos horizontes e novas visões em torno da natureza. A Carta da Terra pode ser usada como um recurso para exercitar o ensino e a aprendizagem em muitos campos e pode ajudar na busca de conexões e inter-relacionamentos entre as varias dimensões da sustentabilidade. "Pode ajudar a melhorar a qualidade da educação, servindo como um veículo para integrar a ética no currículo". (EARTH CHARTER INTERNATIONAL, 2009, p. 2)

Há muitas maneiras de utilização da Carta da Terra na educação, dependendo do contexto e dos interesses do educador e do aluno. Os objetivos, também são muitos, conforme demonstra o Guia de utilização da Carta da Terra, produzido pela Earth Charter International (2009):

1. Aumentando a conscientização e a compreensão de problemas globais críticos - A Carta da Terra pode ser usada para desenvolver 
a capacidade de pensamento crítico e para aumentar a conscientização e a compreensão de professores e alunos sobre os problemas ambientais (...);

2. Promovendo diálogos sobre os valores e princípios de uma maneira de vida sustentável - Objetivos comuns e valores compartilhados formam as bases de uma comunidade forte $e$ saudável, (...);

3. Promovendo o desenvolvimento ético dos indivíduos - Usando a Carta da Terra para aumentar a conscientização, desenvolver a compreensão de problemas globais críticos e promover diálogos sobre objetivos comuns, (...);

4. Inspirando um espírito de colaboração, cooperação e ação - A Carta da Terra conclui com um pedido de ação através de, entre outras coisas, novas parcerias entre a sociedade civil, os negócios e o governo em todos os níveis. (...);

5. Encorajando uma visão "biossensível" - Muitos dos princípios da Carta da Terra podem ser usados para ajudar professores e alunos a se tornarem mais conscientes e entenderem melhor a importância da biodiversidade, (...);

6. Aplicando valores e princípios - A parte principal da Carta da Terra recomenda ação e funciona como um guia para maneiras mais sustentáveis de viver. (...);

7. Facilitando um entendimento dos relacionamentos entre a Carta da Terra, políticas públicas e leis internacionais - Enquanto a Carta da Terra é uma carta escrita por meio de processo de consulta aberto e participativo, onde ela também pode ser entendida como um documento de "lei suave" internacional. (...);

8. Auxiliando instituições e sistemas educacionais na reorientação de seu ensino e operações para maneiras sustentáveis de viver - A Carta da Terra tem inspirado muitos recursos educacionais para o ensino e aprendizado voltado para um futuro sustentável e para avaliar as práticas de sustentabilidade de instituições educacionais. (...). (EARTH CHARTER INTERNATIONAL, 2009, p. 5-6)

Para demonstrar essas possibilidades e promover uma discussão sobre a utilização da Carta da Terra, está anexado a este trabalho um livro preparado com padrões voltados à educação Ambiental e que pretende alcançar propostas de interesse entre jovens, em relação a preservação do meio ambiente, através da ética, do respeito e da relação indivíduo/natureza. 


\section{DIFICULDADES E DESAFIOS}

A proposta inicial, sobretudo, é apresentar a oportunidade do tema para a educação de crianças e jovens, estendida às famílias que alicerçam a formação global de seus filhos. Sabe-se que a escola, enquanto multiplicadora de competências, se utiliza de instrumentos para formar indivíduos ativos e conscientes e não somente repetidores de saberes formais e curriculares. $O$ interesse pedagógico em se discutir a Carta da Terra, é apoiar e contribuir para que o docente explore temas transversais vinculados à sustentabilidade e à preservação ambiental, em diferentes momentos de seu planejamento. É um instrumento que se apresenta como declaração de princípios fundamentais para a construção de uma sociedade em busca de justiça, democracia e paz.

O apelo para a reflexão sobre os problemas ambientais está presente durante toda a leitura do documento, proposto no projeto. $E$ traz a atenção da criança para o conhecimento da Carta da Terra, como um valoroso instrumento para a conscientização da preservação ambiental, sustentabilidade e a importância de viver num mundo com princípios de justiça e paz entre os indivíduos.

Muitas vezes encontra-se um cenário que desmotiva os professores em trabalhar a Educação Ambiental, pois a política desse trabalho ainda não saiu do papel na maioria das escolas, e se limita em projetos ou datas emblemáticas. Há falta de espaço, material, planejamento entre disciplinas, qualificação profissional, e consequentemente a temática abordada se torna confusa e deficiente no espaço escolar, privilegiando-se o plano teórico, e sem discussão necessária pela observação dos espaços de vivência pelo aluno.

[...] esse alerta é relevante, uma vez que se observam, nos diferentes eventos específicos da E. A., relatos de experiências escolares e descrições de projetos e iniciativas, incluindo dificuldades cotidianas e estruturais. Aqui se afirma claramente que a institucionalização e a universalização da E. A. nas escolas dependem, portanto, para além da motivação dos trabalhadores da educação e dos educandos, de políticas públicas e de recursos (financeiros e humanos), sem os quais não se garante sua efetiva incorporação ao currículo e à gestão escolar. (CRUZ-LAMOSA; LOUREIRO, 2011, p. 282) 
Seria necessário que houvesse iniciativa de todos os personagens envolvidos para que a Educação Ambiental ultrapassasse os muros da escola e percorresse em novas oportunidades para a formação de indivíduos com atitudes e responsabilidades na preservação do meio ambiente e sustentabilidade.

E a Carta da Terra vem favorecer essa iniciativa. Por meio da mediação do professor, ela oportuniza uma perspectiva mais abrangente aos problemas ambientais do Planeta e uma reflexão da necessidade de mudança de comportamento para a garantia de um futuro mais sustentável.

\section{CONSIDERAÇÕES FINAIS}

A vida do homem na terra tem passado por inúmeras mudanças, sejam elas no sentido biológico, psicológico, social ou cultural. A evolução é inevitável pelos acontecimentos históricos, mas o impacto dessa historicidade, em um conquistar contínuo, seja individual ou coletivo, conduz a várias transformações do meio ambiente, colocando em risco a sua própria perpetuação. (GADOTTI, 2000).

É preciso a conscientização de todas as pessoas em relação a necessidade urgente de uma Educação Ambiental, principalmente nos anos iniciais do ensino, para que a construção de valores éticos, sejam garantidores de princípios para um futuro sustentável.

A Carta da Terra, como ferramenta pedagógica, criará subsídios para que no contexto da educação básica, consiga estimular nas crianças e jovens, os valores socioambientais para uma vida mais igualitária e inclusiva.

Apesar de todas as dificuldades que as escolas apresentam, espera-se que a Educação Ambiental seja uma realidade praticada nas escolas, e que faça parte do planejamento na fase inicial da educação, principalmente com as crianças a partir de 8 anos, pois é o momento em que surgem as descobertas e a autonomia de suas ideias para a formação de indivíduos de ação, e conscientes do seu papel em diferentes espaços. 


\section{REFERÊNCIAS}

ARAGUAIA, Mariana. Piaget e o desenvolvimento moral na criança. Brasil Escola, [2015?] Disponível em: <http://brasilescola.uol.com.br/biografia/piagetdesenvolvimento-moral-na-crianca.htm>. Acesso em: 16 nov. 2016.

ARANHA, Maria Lúcia de Arruda; MARTINS, Maria Helena Pires. Filosofando: Introdução à Filosofia. $3^{a}$ ed. São Paulo: Moderna, 2003.

BOFF, Leonardo. Sustentabilidade e Educação. leonardoboff.com, maio 2012. Disponível em: <https://leonardoboff.wordpress.com/2012/05/06/sustentabilidade-eeducacao/>. Acesso em: 9 fev. 2017.

BRASIL. MEC. Diretrizes Curriculares do Curso de Pedagogia. Ministério da Educação/ Conselho Nacional de Educação (CNE), 2006.

Parâmetros Curriculares Nacionais: Ensino Médio. Ministério da Educação/ Brasília, 1999.

. MEC. Meio ambiente: debate na internet. set. 2008. Disponível em: <http://portal.mec.gov.br/busca-geral/202-noticias/264937351/11257-sp1039270908>. Acesso em: 9 fev. 2017.

. MEC. Proposta de Diretrizes Curriculares Nacionais para a Educação Ambiental/2013. Disponível em: <http://portal.mec.gov.br/dmdocuments/publicacao13.pdf>. Acesso em: 9 fev. 2017.

COIMBRA, Audrey de Souza. Interdisciplinaridade e Educação Ambiental: Integrando seus princípios necessários. [2010]. Disponível em: <http://www.ufjf.br/virtu/files/2010/03/artigo-1a2.pdf>. Acesso em: 25 jan. 2017. Artigo apresentado a Universidade Federal de Juiz de Fora - UFJF em 2010.

CRUZ-LAMOSA, R. A.; LOUREIRO, C. F. B. A Educação Ambiental e as políticas educacionais: um estudo nas escolas públicas de Teresópolis (RJ). Educação e Pesquisa, São Paulo, v. 37, n. 2, p. 279-292, mai/ago. 2011.

CURRY, Patrick. Ecological ethics: an intoduction. Cambridge: Polity, 2011.

DÍAZ-AGUADO, M. J.; MEDRANO, C. Construção moral e educação: uma aproximação construtivista para trabalhar os conteúdos transversais. Bauru: Edusc, 1999.

EARTH CHARTER INTERNATIONAL. Um Guia para Usar a Carta da Terra na Educação. 2009. Disponível em: http://www.dhnet.org.br/dados/guias/edh/guia_usar_carta_terra_na_educacao.pdf>. Acesso em: 9 fev. 2017. Versão 1/ abril de 2009. 
FAZENDA, I. C. A. Integração e interdisciplinaridade no ensino brasileiro: efetividade ou ideologias. 5.ed. São Paulo: Edições Loyola, 2002.

FERRERO, Elisabeth M; HOLLAND, Joe. Carta da terra: reflexão pela ação. Trad. Roberto Cattani. São Paulo: Cortez, 2004.

GADOTTI, Moacir. Pedagogia da Terra. São Paulo: Editora Fundação Petrópolis, 2000. . Educar para a sustentabilidade. São Paulo: Instituto Paulo Freire, 2009. Freire, 2010.

. A Carta da Terra na educação. São Paulo: Editora e. Livraria Instituto Paulo GALVÃO, IZABEL. Henri Wallon: uma concepção dialética do desenvolvimento infantil. $7^{\mathrm{a}}$.ed. Petrópolis, RJ: Vozes, 2000. (Educação e conhecimento).

IMBERT, F. A questão da ética no campo educativo. Petrópolis: Vozes, 2002.

KOHLBERG, L. The Development of Moes of Moral Thinking and Choice in the Years Ten to Sixteen., University of Chicago, 1958. Unpublished doctoral dissertation

LA ROVÈRE, A.L.; VIEIRA, L. (Org.) Tratados das ONG's aprovados no Fórum Internacional de ONG's e Movimentos Sociais no âmbito do Fórum Global: Tratado sobre Consumo e Estilo de Vida. Rio de Janeiro, Fórum Brasileiro de ONG's e Movimentos Sociais para o Meio Ambiente e Desenvolvimento, 1992.

MENIM, Maria S. de Stefano. Escola e Educação Moral. In: Coleção Educação e Psicologia em Debate. Campinas: Mercado de Letras Edições e Livraria Ltda, 2007.

MOREIRA, Marco Antônio. Teorias de Aprendizagens, EPU, São Paulo, 1995.

PCN. Parâmetros Curriculares Nacionais: Ensino Médio. Brasília: Ministério da Educação, 1999.

PEREIRA, Francielle Amâncio. Educação ambiental e interdisciplinaridade: avanços e retrocessos. 2014. Disponível em: $<$ http://www.seer.ufu.br/index.php/braziliangeojournal/article/view/27441/ 15657>. Acesso em: 16 nov. 2016. Artigo publicado em 2014 na Universidade Federal de Uberlândia- UFU.

PIAGET, Jean. O juízo moral na criança. Trad. Elzon L. 2. ed. São Paulo: Summus, 1994. 
. O desenvolvimento do pensamento: equilibrarão das estruturas cognitivas. Lisboa: Dom Quixote,1997.

QUINTAS, J. S. Por uma educação ambiental emancipatória: considerações sobre a formação do educador para atuar no processo de gestão ambiental. In: QUINTAS, J. S. (Org.). Pensando e praticando a educação ambiental na gestão do meio ambiente. Brasília: IBAMA, 2000. p. 11-19.

TAVARES, F. J. P. A Educação Ambiental na Formação Inicial de Professores de Educação Física. Rio Grande: 2002. Dissertação de Mestrado (Programa de Mestrado em Educação Ambiental) - FURG.

TERRA, Márcia Regina. O desenvolvimento humano na teoria de Piaget. 2006. Disponível em:

<http://www.unicamp.br/iel/site/alunos/publicacoes/textos/d00005.htm>. Acesso em: 25 jan. 2017.

VYGOTSKY, LEV S. Pensamento e linguagem. São Paulo: Martins Fontes, 1987. (Coleção Psicologia e Pedagogia).

A formação social da mente: o desenvolvimento dos processos psicológicos superiores. $3^{a}$.ed. São Paulo: Martins Fontes, 1989. 168p. (Coleção Psicologia e Pedagogia. Nova Série).

WALLON, H. A evolução psicológica da criança. Lisboa: Edições 70, 1995. 